\title{
A simple way to nickel based mesoporous carbons: Inexpensive nanocatalysts for the hydrogenolysis of sorbitol
}

\section{Ying Yang*}

State Key Laboratory of Heavy Oil Processing, China University of Petroleum, No.18, Fuxue Road,Changping District, Beijing 102249, China

\section{Article Info \\ *Corresponding author: Dr. Ying Yang \\ State Key Laboratory of Heavy Oil Processing \\ China University of Petroleum No.18, Fuxue Road, Changping District Beijing 102249, China Tel: +86-10-89734979 \\ E-mail: catalyticscience@163.com}

\section{Received: September 29, 2018}

Accepted: November 8, 2018

Published: November 15, 2018

Citation: Yang Y. A simple way to nickel based mesoporous carbons: Inexpensive nanocatalysts for the hydrogenolysis of sorbitol. Int J Petrochem Res. 2018; 2(3): 194-201.

doi: 10.18689/ijpr-1000135

Copyright: @ 2018 The Author(s). This work is licensed under a Creative Commons Attribution 4.0 International License, which permits unrestricted use, distribution, and reproduction in any medium, provided the original work is properly cited.

Published by Madridge Publishers

\begin{abstract}
Non-precious nanocatalysts are of great importance both academically and industrially owing to their low cost and high performance in various reactions. Here in we report novel nickel based mesostructured carbon materials bearing homogeneously distributed nickel nanoparticles embedded inside the carbonaceous framework synthesized via fabrication of $\mathrm{P} 123$-directed chitosan-nickel superamolecular aggregates before pyrolysis. The mesostructure of support, and the dispersion, crystal and local structures of embedded nickel nanoparticles are fully examined by comprehensive characterization techniques, such as small-angle X-ray scattering, $\mathrm{N}_{2}$ adsorption/ desorption, TEM, high energy $\mathrm{X}$-ray diffraction and X-ray absorption fine structure. All nickel based mesostructured carbons are active in the hydrogenolysis of sorbitol. Superior activity, total selectivity to 1,2-propylene glycol (1,2-PG) and ethylene glycol $(E G)$, and recycling stability are shown when the molar ratio of $\mathrm{Ni} / \mathrm{CTS}$ in the synthetic gel is $1 / 2$ and the pyrolysis temperature is $550^{\circ} \mathrm{C}$, which can be ascribed to the controlled fabrication of uniform spherical nickel nanoparticles on the mesoporous carbon. This work may open new avenues for designing efficient metal catalysts by fabrication of surfactant-directed metal complex-containing superamolecular aggregates before pyrolysis.
\end{abstract}

Keywords: Self-assembly, Mesoporous carbon, Nickel, Sorbitol hydrogenolysis, 1,2-propylene glycol

\section{Introduction}

Conversion of biomass platform molecules into commodity chemicals has received extensive attention owing to the scarcity and high expense of fossil resources [1-4]. Among this line, the hydrogenolysis of renewable sorbitol to produce high value-added chemicals, like 1,2-propylene glycol (1,2-PG) and ethylene (EG), is a promising green process and is of great demand for producing polymers, resins, pharmaceuticals, cosmetics and functional fluids, etc [5]. Various heterogeneous nanocatalysts, such as $\mathrm{Ni}, \mathrm{Ru}, \mathrm{Pd}$ and $\mathrm{Pt}$, have been designed for this process [6-9]. Non-precious nickel catalysts are superior to noble metal catalysts, since their usage can reduce cost fundamentally compared with using noble or doped noble metal catalysts. Correspondingly, various $\mathrm{Ni}$-containing catalysts such as $\mathrm{Ni}$-Kisseslguhr, $\mathrm{Ni} / \mathrm{SiO}_{2^{\prime}} \mathrm{Ni} /$ $\mathrm{Al}_{2} \mathrm{O}_{3^{\prime}} \mathrm{Ni} / \mathrm{TiO}_{2^{\prime}}, \mathrm{Ni} / \mathrm{ZrO}_{2^{\prime}} \mathrm{Ni} / \mathrm{MgO}, \mathrm{Ni}-\mathrm{NaY}$ and $\mathrm{Ni}-\mathrm{Ce} / \mathrm{Al}_{2} \mathrm{O}_{3^{\prime}}$ have been extensively synthesized and evaluated as catalysts for cellulose conversion, glucose hydrogenation, as well as sorbitol and glycerol hydrogenolysis owing to their inexpensive nature $[6,8,10-13]$. However, recent advances in synthesis of such catalysts focus on wetness 
impregnation of nickel ions onto pre-formed metallic oxide support followed by reduction in $\mathrm{H}_{2}$ atmosphere. This tedious post-synthetic method renders instable catalysts with unevenly dispersed Ni nanoparticles (Ni NPs) on the external surface or near pore mouths, even more worse, these oxide supports readily dissolves at elevated $\mathrm{pH}$ [6]. Despite continuous efforts, fabrication of homogeneously distributed $\mathrm{Ni}$ NPs onto a stable support via an economic synthetic procedure still remains a great challenge.

Carbon material is one of the best choices as the catalyst support due to its excellent chemical and hydrothermal stability, and large surface area for dispersing active components [14]. Particularly, mesoporous carbon (MC) materials offer great advantages over conventional activated carbons (AC) owing to their well-controlled mesopore structures, which are favorable to large molecule transportation [15]. However, mesoporous carbon (MC) supported metal catalysts are also prepared via traditional wetness impregnation before reduction, during which the $\mathrm{MC}$ must be elaborately fabricated by a tedious hard-templating approach. To replace such conventional "low efficient" preparations, pyrolysis of metal coordination polymers or metal organic frameworks under inert atmosphere is proved to be step-economic to in situ construct homogeneously dispersed metal nanoparticles inside the carbonaceous matrix, since the metal nanoparticles and carbonaceous matrix are synchronously fabricated during pyrolysis [16-17]. Whereas, the resulting carbonaceous frameworks are always microporous, disordered and lack of uniform pore size distributions, thus blocking mass transportation. To combine carbonaceous mesostructures with homogeneously dispersed metal nanoparticles, blending the thinking of mesopore formation via pyrolysis of surfactant-directed self-assemblies into pyrolysis of dispersion-controlled metal coordination polymers may be constructive.

To verify the hypothesis above, herein we try to synthesize a series of homogeneously distributed nickel based mesoporous carbons by pyrolysis of chitosan-nickel superamolecular aggregates, constructed by P123-directed self-assembly of 8-quinolinol modified chitosan (CTS-HQ) and nickel acetate with different $\mathrm{Ni} / \mathrm{CTS}$ molar ratios under neutral conditions. Chitosan is preferentially chosen as carbon source and superior to the commonly used phenolic resin, polyamine, etc, since this naturally-occurring macromolecule is very abundant biodegradeble and biocompatible polysaccharide from alkaline deacetylation of chitin [18]. In this work, chitosan is pre-modified by 8-quinolinol to afford CTS-HQ, and to facilitate its binding and dispersion of metal ions more efficiently in sol-gel process, as well as its marriage with PEO moieties through $\mathrm{H}$-bonding interaction well, rendering firmly fabricated superamolecular aggregates. The following pyrolysis under inert atmosphere at different temperatures is a unique "one stone, three birds" methodology to remove P123, carbonize CTS and reduce nickel ions by a single step. The resulting nickel catalysts are carefully characterized and screened as catalysts in the hydrogenolysis of sorbitol. The aim of this study is to develop a novel methodology for metal based mesoporous carbon design.

\section{Experimental}

\section{Catalyst preparation}

Nickel based mesoporous carbons were in situ prepared via pyrolysis of P123-directed chitosan-nickel superamolecular aggregates. First, CTS-HQ was facilely synthesized from 5-chloromethyl-8-quinolinol hydrochloride (1), involving only a two-step chemical transformation from 8-quinolinol (see Supporting Information and Figure S1-5).

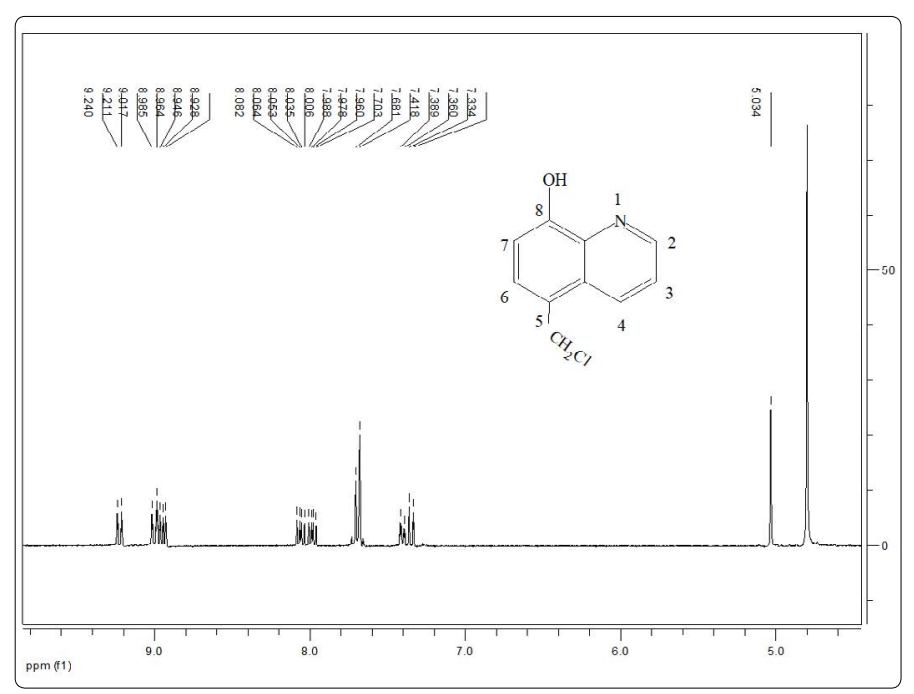

Figure S1. ${ }^{1} \mathrm{H}$ NMR spectrum of 1.

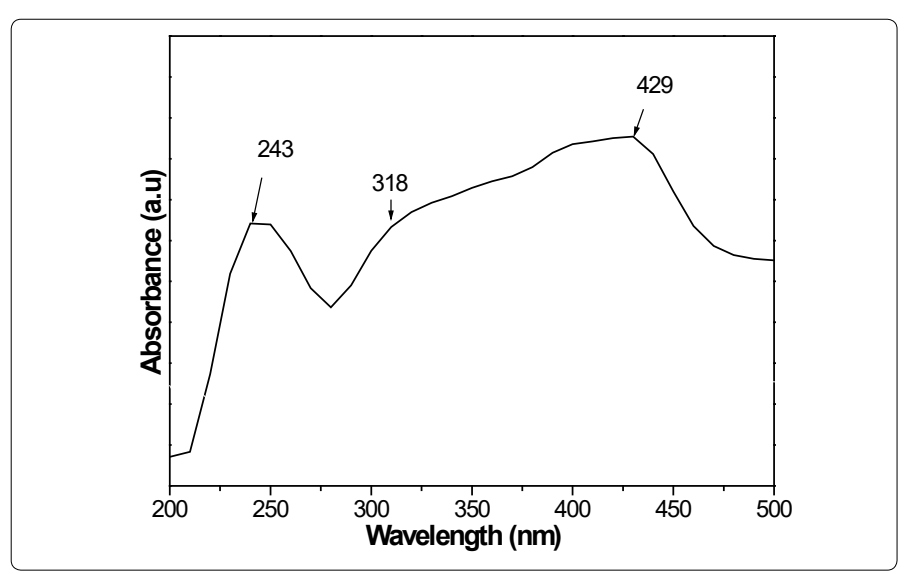

Figure S2. UV-vis spectrum of 1.

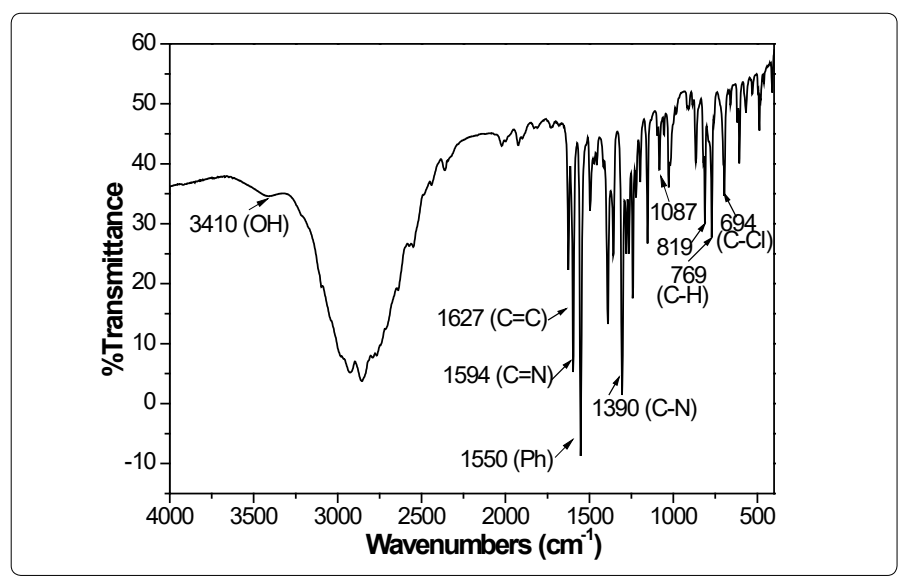

Figure S3. FT-IR spectrum of 1. 


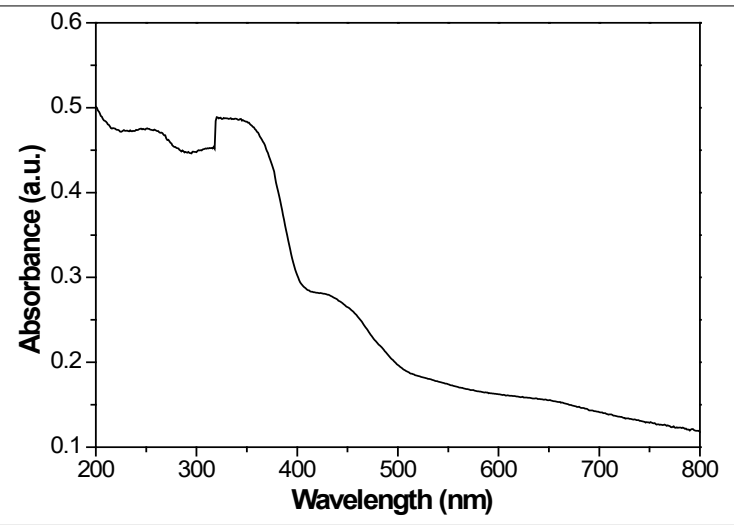

Figure S4. UV-vis spectrum of CTS-HQ.

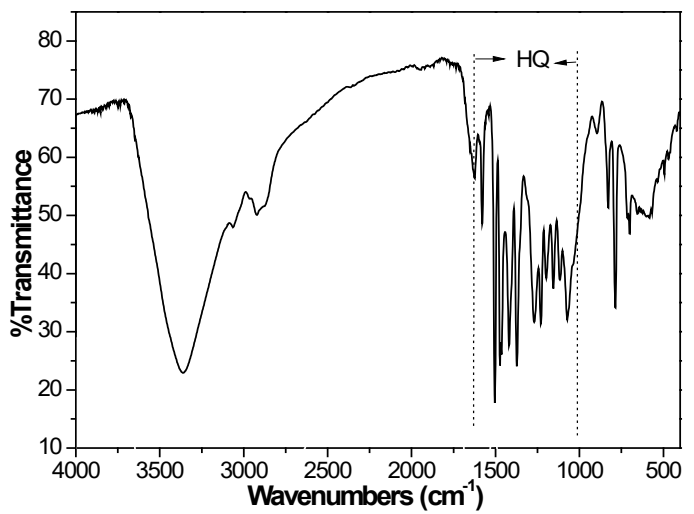

Figure S5. FT-IR spectrum of CTS-HQ.

$\mathrm{CTS}-\mathrm{HQ}$ and $\mathrm{Ni}\left(\mathrm{CH}_{3} \mathrm{COO}\right)_{2} \cdot 4 \mathrm{H}_{2} \mathrm{O}$ were respectively used as carbon source and metal precursor for the synthesis of precursor composite, Ni/CTS-P-x by P123-directed self-assembly (Scheme 1).

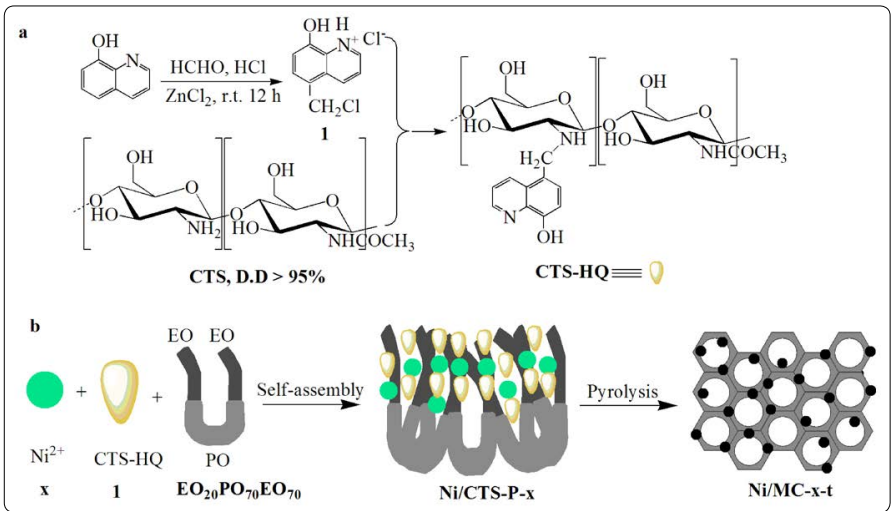

Scheme 1. Schematic illustrating of nickel based mesoporous carbon preparation. (a) Synthesis of 5-chloromethyl-8-quinolinol (1) and 8-quinolinol modified chitosan (CTS-HQ). (b) Fabrication of P123-directed precursor composite Ni/CTS-P-x before pyrolysis, yielding Ni/MC-x-t.

The molar ratio of the precursor gel in the preferred preparation is: $1 \mathrm{CTS}-\mathrm{HQ}: x \mathrm{Ni}\left(\mathrm{CH}_{3} \mathrm{COO}\right)_{2} \cdot 4 \mathrm{H}_{2} \mathrm{O}: 0.017 \mathrm{P} 123: 66.5$ $\mathrm{H}_{2} \mathrm{O}: 19.6 \mathrm{EtOH}$, where $x$ represents the $\mathrm{Ni} / \mathrm{CTS}$ molar ratio, and was set to be $1 / 1,1 / 2$ and $1 / 4$. In a typical synthesis, $2.0 \mathrm{~g}$ of $\mathrm{P} 123$ was dissolved in $48 \mathrm{ml}$ of ethanol-water $(50 \%, \mathrm{~V} / \mathrm{V})$ and stirred at $40^{\circ} \mathrm{C}$ for $1 \mathrm{~h}$, followed by addition of $2.32 \mathrm{~g}$ of CTS-HQ combined with certain amount of $\mathrm{Ni}\left(\mathrm{CH}_{3} \mathrm{COO}\right)_{2} \cdot 4 \mathrm{H}_{2} \mathrm{O}$. The resulting mixture was stirred at $40{ }^{\circ} \mathrm{C}$ for $20 \mathrm{~h}$ and then transferred into a polypropylene bottle and reacted at $100{ }^{\circ} \mathrm{C}$ under static conditions for $48 \mathrm{~h}$. The as-made product was washed, dried and pyrolyzed in a tubular furnace under $\mathrm{N}_{2}$ atmosphere. The heating rate was $2^{\circ} \mathrm{C} /$ min below $250^{\circ} \mathrm{C}$ and $5^{\circ} \mathrm{C} /$ min above $250^{\circ} \mathrm{C}$, and pyrolysis was carried out at 550, 750 and $950{ }^{\circ} \mathrm{C}$ for $2 \mathrm{~h}$, respectively. The resulting solid was denoted as $\mathrm{Ni} / \mathrm{MC}-\mathrm{x}-\mathrm{t}$, where $t$ represents the carbonization temperature.

\section{Catalytic hydrogenolysis of sorbitol}

The hydrogenolysis of sorbitol was carried out in a $100 \mathrm{ml}$ stainless steel (SS) autoclave (Parr 4843) containing of $5.5 \mathrm{~g}$ of an aqueous solution of $9 \mathrm{wt} \%$ sorbitol, $0.5 \mathrm{~g} \mathrm{CaO}$ and $0.05 \mathrm{~g}$ nickel based catalyst. The sealed autoclave was purged by flowing $\mathrm{H}_{2}$ at room temperature. The autoclave was pressurized with $\mathrm{H}_{2}$ to 6 $\mathrm{MPa}$ and was heated to $220^{\circ} \mathrm{C}$. Once the temperature was reached, the timing was started. During the reaction, the $\mathrm{H}_{2}$ pressure in the autoclave kept constant due to the small amount of $\mathrm{H}_{2}$ consumed. After being finished, the autoclave was cooled rapidly with cold water. Then a certain amount of 1,4-dioxane was added as the internal standard, and analyzed. Polyols were analyzed using a 6820 Gas Chromatography (GC) with a capillary column (AT ${ }^{\mathrm{T}}$-AQUAWAX). Sorbitol was analyzed by HPLC (HPLC 1260, Agilent) equipped with an ELSD detector (ELSD-3000, Alltech) and a Prevail ${ }^{\mathrm{TM}}$ Carbohydrate ES HPLC Column at $25^{\circ} \mathrm{C}$. Redistilled water/acetonitrile (15/85) mixture was used as the mobile phase at a flow rate of $0.9 \mathrm{ml} \mathrm{min}^{-1}$.

\section{Results and discussion}

\section{Structural properties}

High-energy X-ray diffraction (HE-XRD) was preferentially used to investigate the crystal structure of $\mathrm{Ni}$ species, due to its high flux and rapid analysis. figure 1 shows the HE-XRD patterns of various $\mathrm{Ni}$-containing samples. As expected, different from nickel acetate, the representative Ni/CTS-P-1/2 shows no diffractions, corresponding to the coordination of $\mathrm{Ni}$ ions with CTS-HQ. Upon pyrolysis, all Ni/MC-x-t samples display XRD patterns of fcc-structured Ni (JCPDS file 04-0805) at (111), (200), (220), (311) and (222) diffractions, indicating the formation of $\mathrm{Ni}$ nanocrystallites [19]. However, the diffraction intensity decreases as the $\mathrm{Ni}$ content in the synthetic gel decreases (Figure 1c-e), and it is the same case when elevating pyrolysis temperature from 550 to $750{ }^{\circ} \mathrm{C}$ (Figure $1 \mathrm{~d}, \mathrm{f}, \mathrm{g}$ ), suggesting less Ni nanocrystals formed.

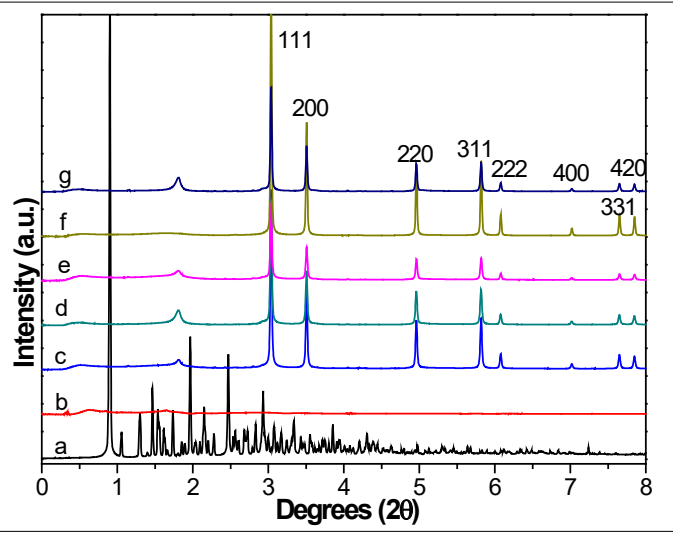

Figure 1. High-energy X-ray diffraction patterns of (a) $\mathrm{Ni}\left(\mathrm{CH}_{3} \mathrm{COO}\right) \cdot 4 \mathrm{H}_{2} \mathrm{O}$,

(b) Ni/CTS-P-1/2, (c) Ni/MC-1/2-550, (d) Ni/MC-1/2-750, (e) Ni/ MC-1/2-950, (f) Ni/MC-1/1-750 and (g) Ni/MC-1/4-750. 
The small-angle X-ray scattering (SAXS) pattern for the representative Ni/MC-1/2-550 shows three well-resolved diffraction peaks at $q$ values of $0.211,0.327$ and $0.437 \AA^{-1}$ with a ratio of 1: $3^{1 / 2}: 2$ (figure S6), associating with 10,11 and 20 reflections of $2 \mathrm{D}$ hexagonal symmetry with the $\mathrm{p} 6 \mathrm{~m}$ space group [20].

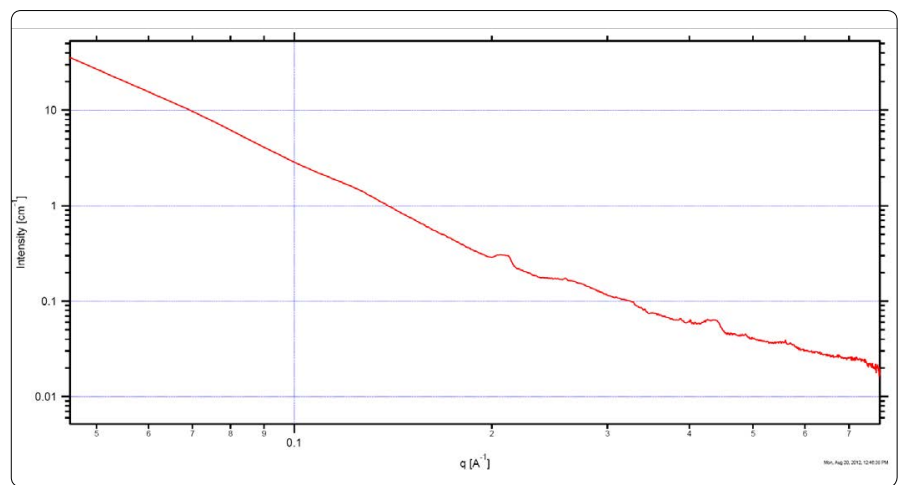

Figure S6. SAXS pattern of Ni/MC-1/2-550.

TEM images of Ni/CTS-1/2-550 shows highly dispersed spherical nanoparticles with average size centered at $34.7 \mathrm{~nm}$ (Figure 2a,d). However, Ni/CTS-1/2-750 and Ni/CTS-1/2-950 do not inherit the initial spherical shapes of Ni NPs, but rather exhibit irregularly congregated NPs with increased average diameter (Figure $2 b, e, c, f)$. HRTEM images show clear lattice fringes throughout the whole particle, and the fringes in (111) direction is $0.203 \mathrm{~nm}$, irrespective of the pyrolysis temperature (Figure $2 \mathrm{~g}, \mathrm{~h}$ ). Correspondingly, the electron microdiffraction of single Ni NP demonstrates the fm-3m symmetrical structure figure $2 \mathrm{i}$ and the selected area electron diffraction (SAED) pattern for Ni/MC-1/2-550 exhibits diffraction rings with fcc polycrystalline figure $2 \mathrm{j}$, confirming XRD findings.

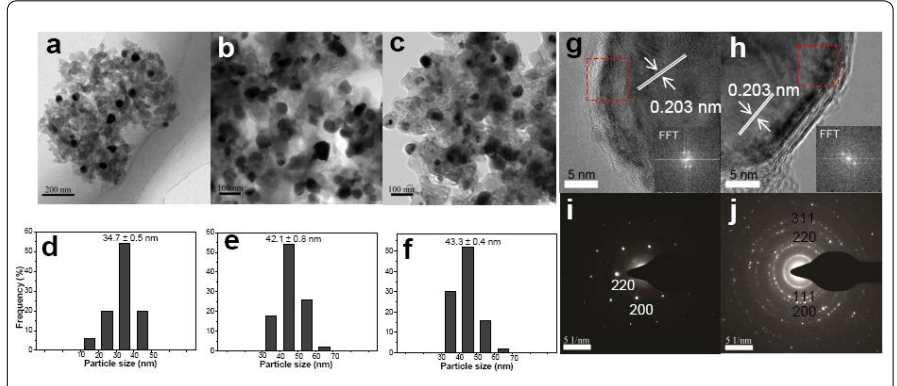

Figure 2. TEM images and the corresponding particle size distributions of $(a, d) \mathrm{Ni} / \mathrm{MC}-1 / 2-550,(b, e) \mathrm{Ni} / \mathrm{MC}-1 / 2-750$ and $(c, f)$ $\mathrm{Ni} / \mathrm{MC}-1 / 2-950$, and HRTEM, electron microdiffraction and selected area electron diffraction images of $(g, i, j) \mathrm{Ni} / \mathrm{MC}-1 / 2-550$ and $(\mathrm{h}) \mathrm{Ni}$ / MC-1/2-750.

\section{Textual properties}

$\mathrm{N}_{2}$ adsorption reveals an IV type isotherm with a sharp inflection step at $P / P_{0}$ ranging from 0.25 to 0.35 (Figue $3 \mathrm{~A}$ ), characteristic of mesoporous materials [21,22].
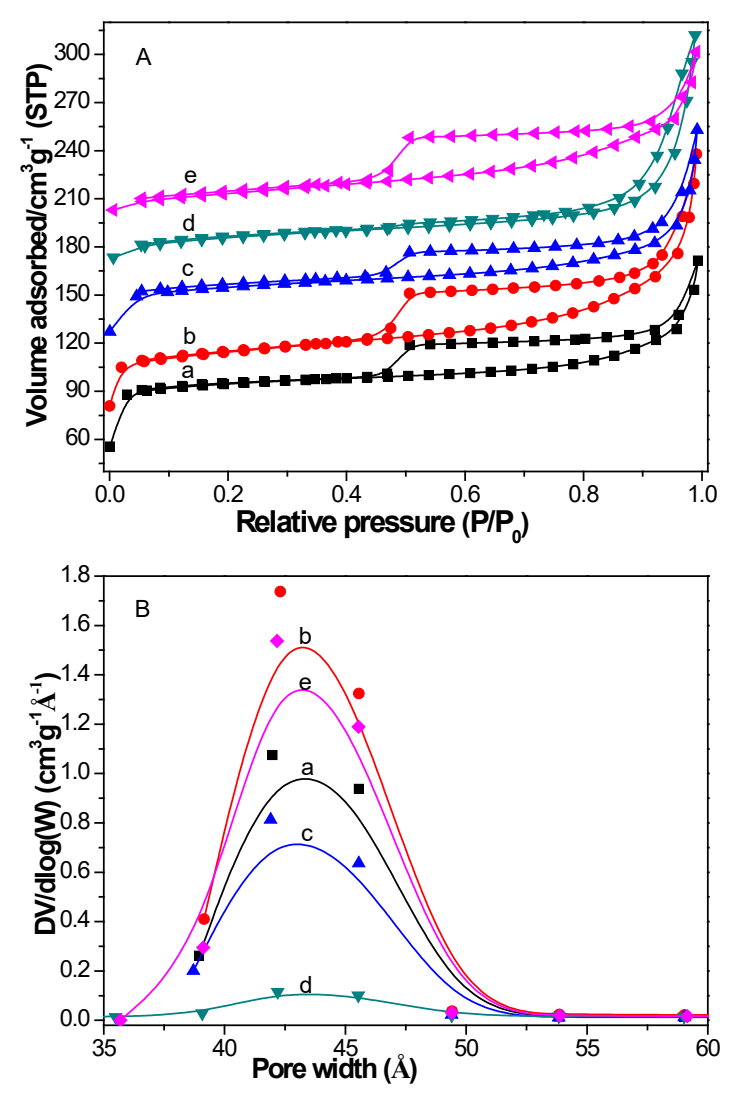

Figure 3. (A) $\mathrm{N}_{2}$ adsorption/desorption isotherms and (B) $\mathrm{BJH}$ pore size distributions of (a) Ni/MC-1/1-750, (b) Ni/MC-1/2-750, (c) Ni/ MC-1/4-750, (d) Ni/MC-1/2-550 and (e) Ni/MC-1/2-950. (b), (c), (d) and (e) were offset for 40,70, 110 and $170 \mathrm{~cm}^{3} \mathrm{~g}^{-1}$, respectively.

Except for Ni/MC-1/2-550, all Ni/MC-x-t samples show $\mathrm{H}_{2}$-type along with $\mathrm{H}_{3}$-type hysteresis loops in higher $\mathrm{P} / \mathrm{P}_{0}$ region according to the IUPAC classification, corresponding to structural bottle-ink pores combined with piled mesopores [22]. The surface areas and pore volumes of the Ni/MC-x-t series vary with the $\mathrm{Ni} / \mathrm{CTS}$ molar ratio and pyrolysis temperature. As shown in (Table 1).

Table 1. Characteristics of Ni/MC- $x$-t series, BET surface area, $S_{B E T}$ $\left(\mathrm{m}^{2} \mathrm{~g}^{-1}\right)$; micropore surface area, $\mathrm{S}_{\text {micro }}\left(\mathrm{m}^{2} \mathrm{~g}^{-1}\right)$; pore volume, $\mathrm{V}_{\mathrm{p}}\left(\mathrm{cm}^{3}\right.$ $\left.\mathrm{g}^{-1}\right)$; micropore volume, $\mathrm{V}_{\text {micro }}\left(\mathrm{cm}^{3} \mathrm{~g}^{-1}\right)$; pore diameter, $\mathrm{D}_{\mathrm{p}}(\mathrm{nm})$ and CHN analysis (wt\%)

\begin{tabular}{|c|c|c|c|c|c|c|c|c|}
\hline \multirow[t]{2}{*}{ Materials } & \multirow{2}{*}{$\begin{array}{c}\mathrm{S}_{\mathrm{BET}} \\
\left(\mathrm{m}^{2} \mathrm{~g}^{-1}\right)^{\mathrm{a}}\end{array}$} & \multirow{2}{*}{$\begin{array}{c}S_{\text {micro }} \\
\left(\mathrm{m}^{2} \mathrm{~g}^{-1}\right)\end{array}$} & \multirow{2}{*}{$\underset{\left(\mathrm{cm}^{3} \mathrm{~g}^{-1}\right)^{\mathrm{b}}}{V_{\mathrm{b}}}$} & \multirow{2}{*}{$\begin{array}{c}V_{\text {micro }} \\
\left(\mathrm{cm}^{3} \mathrm{~g}^{-1}\right)^{c}\end{array}$} & \multirow{2}{*}{$\begin{array}{c}D_{p} \\
(n m)^{d}\end{array}$} & \multicolumn{3}{|c|}{$\begin{array}{l}\mathrm{CHN} \text { analysis } \\
\text { (wt\%) }\end{array}$} \\
\hline & & & & & & $C$ & $\mathrm{H}$ & $\mathrm{N}$ \\
\hline $\mathrm{Ni} / \mathrm{MC}-1 / 1-750$ & 301.9 & 246.4 & 0.237 & 0.115 & 4.32 & - & - & - \\
\hline $\mathrm{Ni} / \mathrm{MC}-1 / 2-750$ & 243.0 & 177.9 & 0.225 & 0.078 & 4.27 & 63.7 & 0.57 & 1.92 \\
\hline $\mathrm{Ni} / \mathrm{MC}-1 / 4-750$ & 271.7 & 214.1 & 0.245 & 0.099 & 4.26 & - & - & - \\
\hline $\mathrm{Ni} / \mathrm{MC}-1 / 2-550$ & 252.8 & 188.6 & 0.249 & 0.081 & 4.33 & 49.3 & 1.04 & 5.54 \\
\hline $\mathrm{Ni} / \mathrm{MC}-1 / 2-950$ & 143.1 & 93.9 & 0.174 & 0.038 & 4.28 & 75.5 & 0.40 & 0.86 \\
\hline
\end{tabular}

${ }^{a}$ The BET surface area was obtained from the adsorption branches in the relative pressure range of 0.05-0.20.

${ }^{\mathrm{b}}$ The single point adsorption total pore volume was taken at the relative pressure of 0.99 .

'Micropore volume was calculated by $t$-plot method.

${ }^{\mathrm{d}}$ The pore size distribution was calculated from the desorption branches by the Barret-Joyner-Halenda (BJH) method.

BET surface areas and pore volumes decrease first from $271.7 \mathrm{~m}^{2} \mathrm{~g}^{-1}$ and $0.245 \mathrm{~m}^{3} \mathrm{~g}^{-1}$ for Ni/MC-1/4-750 to $243.0 \mathrm{~m}^{2} \mathrm{~g}^{-1}$ 
and $0.225 \mathrm{~m}^{3} \mathrm{~g}^{-1}$ for Ni/MC-1/2-750, respectively, and then increase to $301.9 \mathrm{~m}^{2} \mathrm{~g}^{-1}$ and $0.237 \mathrm{~m}^{3} \mathrm{~g}^{-1}$ for Ni/MC-1/1750. On the other hand, they show a decrease trend when elevating pyrolysis temperature from 550 to $950{ }^{\circ} \mathrm{C}$ for $\mathrm{Ni} / \mathrm{MC}-1 / 2-\mathrm{t}$ series, and the $\mathrm{N}$ content also decreases correspondingly owing to the more amine fragments being removed. Whereas, all Ni/MC-x-t samples show pore sizes around $4.30 \mathrm{~nm}$ figure $3 \mathrm{~B}$, probably that Ni NPs are mainly embedded into the carbonaceous framework.

\section{FT-IR studies}

As illustrated in figure $\mathrm{S7}$, the precursor composite $\mathrm{Ni} /$ CTS-P-1/2 shows C-H stretches at 2970 and $2926 \mathrm{~cm}^{-1}$ ascribed to PPO and PEO moieties for surfactant P123, and characteristic phenyl and byridyl vibrations between 1600 and $1300 \mathrm{~cm}^{-1}$, suggesting that CTS-HQ has been incorporated into P123-directed superamolecular aggregates [23-24]. However, these peaks disappear after the simultaneous P123 removal and CTS carbonization upon being pyrolyzed at 750 and $950^{\circ} \mathrm{C}$, though there is some residue when pyrolyzed at $550^{\circ} \mathrm{C}$.

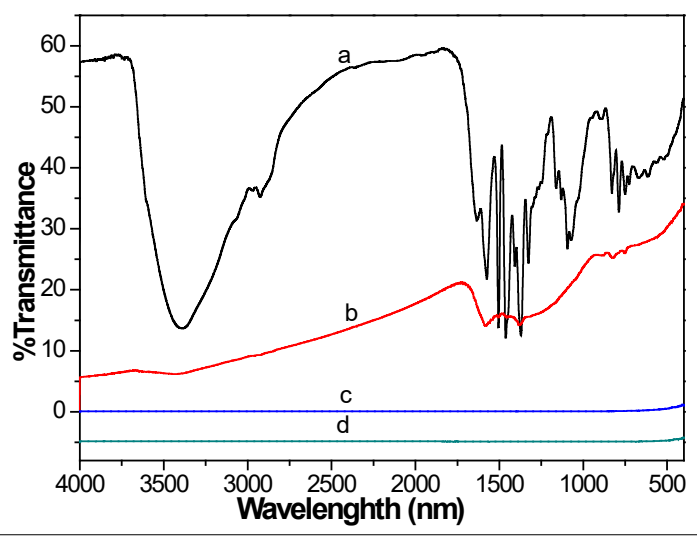

Figure S7. FT-IR spectra of (a) Ni/CTS-P-1/2, (b) Ni/MC-1/2-550, (c) $\mathrm{Ni} / \mathrm{MC}-1 / 2-750$ and (d) Ni/MC-1/2-950.

\section{$\mathrm{X}$-ray absorption fine structure}

Nickel specific X-ray absorption fine structure (XAFS) were carried out to explore the local structure ranged from 1 to $3 \AA$, since the local structural information may closely correlate with catalytic properties. As illustrated in figure $4 \mathrm{~A}$, compared to nickel acetate and Ni/CTS-P-1/2, Ni/MC-x-t samples exhibit the decreased white line intensity along with the newly present pre-edge peak at ca. $8320 \mathrm{eV}$, suggesting the $\mathrm{Ni}(+2)$ species are mostly reduced [25-26], though Ni NPs carry some positive charges because of a slightly positive shifted edge position as compared to Ni reference [27]. In the corresponding $k$ space, Ni/MC-x-t series show clear oscillations at a higher $\mathrm{k}$ region of $\mathrm{k}>8 \AA^{-1}$ as compared to nickel acetate and $\mathrm{Ni} / \mathrm{CTS}-\mathrm{P}-1 / 2$ figure $\mathrm{S} 8$, indicating the dominance of high $\mathrm{Z}$ backscatters, which would be $\mathrm{Ni}$ in our system. Consistently, Ni/MC-x-t series show prominent $\mathrm{Ni}-\mathrm{Ni}$ contributions centered at $2.2 \AA$, different from the dominated $\mathrm{Ni}-\mathrm{O} / \mathrm{C}$ pairs at ca. $1.6 \AA$ for $\mathrm{Ni}(+2)$-containing samples (Figure $4 \mathrm{~B})$.
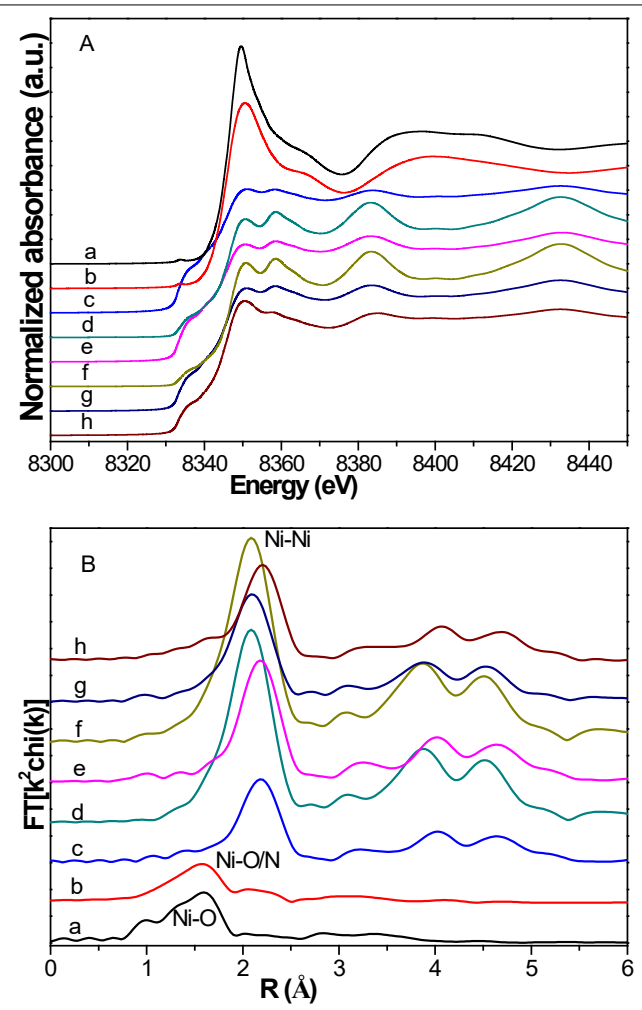

Figure 4. Ni K-edge XANES and the corresponding FT-EXAFS spectra for (a) $\mathrm{Ni}\left(\mathrm{CH}_{3} \mathrm{COO}\right)_{2} \cdot 4 \mathrm{H}_{2} \mathrm{O}$, (b) Ni/CTS-P-1/2, (c) Ni/ MC-1/2-550, (d) Ni/MC-1/2-750, (e) Ni/MC-1/2-950, (f) Ni/ MC-1/1-750, (g) Ni/MC-1/4-750 and (h) Ni foil

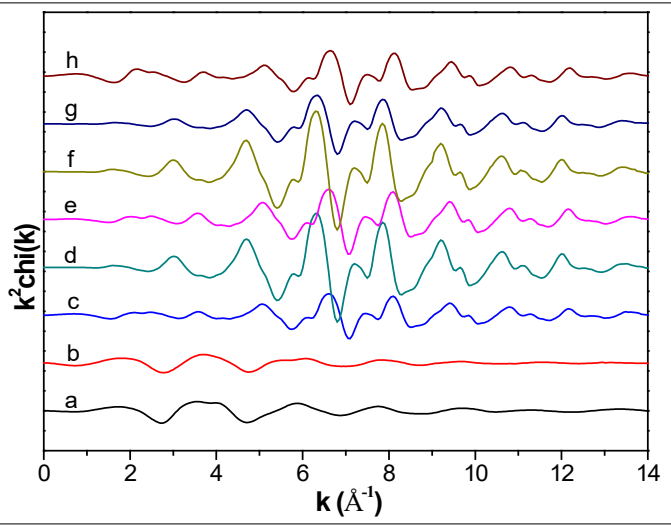

Figure S8. Normalized EXAFS (Ni K-edge scan) plotted as $\mathrm{k}^{2 *} \mathrm{chi}(\mathrm{k})$ vs $\mathrm{k}$ for (a) $\mathrm{Ni}\left(\mathrm{CH}_{3} \mathrm{COO}\right)_{2} \cdot 4 \mathrm{H}_{2} \mathrm{O}$, (b) Ni/CTS-P-1/2, (c) Ni/MC-1/2-550, (d) Ni/MC-1/2-750, (e) Ni/MC-1/2-950, (f) Ni/MC-1/1-750, (g) Ni/ $\mathrm{MC}-1 / 4-750$ and $(\mathrm{h}) \mathrm{Ni}$ foil.

On the other hand, Ni-Ni peak intensity varies with the Ni/CTS molar ratio and pyrolysis temperature. The peak intensity is proportional to the coordination number. As illustrated in (Table 2),

Table 2. Best fit parameters obtained from the analysis of the $\mathrm{Ni}$ K-edge EXAFS spectra ${ }^{a}$

\begin{tabular}{|c|c|c|c|c|c|c|c|c|}
\hline Materials & Shell & $\begin{array}{l}\text { Fitting } \\
\text { range } \\
\Delta r[\AA]]\end{array}$ & $\mathrm{CN}$ & $\mathrm{R}[\AA]$ & $\sigma^{2}\left[\AA^{2}\right]$ & $\begin{array}{l}\Delta \mathrm{E}_{0} \\
{[\mathrm{eV}]}\end{array}$ & $\mathrm{S}_{0}^{2}$ & $\begin{array}{c}\text { R-factor } \\
(\%)\end{array}$ \\
\hline $\mathrm{Ni} / \mathrm{MC}-1 / 2-550$ & $\mathrm{Ni}-\mathrm{Ni}$ & $1.19-2.92$ & 5.5 & 2.48 & 0.00575 & 4.876 & 1.378 & 0.061 \\
\hline $\mathrm{Ni} / \mathrm{MC}-1 / 2-750$ & $\mathrm{Ni}-\mathrm{Ni}$ & $1.01-2.85$ & 7.3 & 2.48 & 0.00750 & -9.138 & 4.321 & 0.010 \\
\hline Ni/MC-1/2-950 & $\mathrm{Ni}-\mathrm{Ni}$ & $1.15-2.66$ & 8.1 & 2.48 & 0.00582 & 4.970 & 2.016 & 0.003 \\
\hline Ni/MC-1/1-750 & $\mathrm{Ni}-\mathrm{Ni}$ & $1.18-2.61$ & 11.2 & 2.48 & 0.00808 & -9.240 & 4.979 & 0.004 \\
\hline $\mathrm{Ni} / \mathrm{MC}-1 / 4-750$ & $\mathrm{Ni}-\mathrm{Ni}$ & $1.16-2.58$ & 6.2 & 2.49 & 0.00629 & -9.121 & 2.065 & 0.011 \\
\hline Ni foil & $\mathrm{Ni}-\mathrm{Ni}$ & - & 12.0 & 2.48 & - & - & - & - \\
\hline
\end{tabular}


The coordination number (curve-fitted values) increases from 5.5 for Ni/MC-1/2-550 figure s9 to 8.1 for Ni/MC-1/2950, indicating larger Ni NPs formed at higher pyrolysis temperature. Increasing $\mathrm{Ni} / \mathrm{CTS}$ molar ratio also brings a raise in coordination number from 6.2 for Ni/MC-1/4-750 to 11.2 for Ni/MC-1/1-750. However, All Ni/MC-x-t samples have smaller coordination numbers than that of $\mathrm{Ni}$ foil $(\mathrm{CN}=12)$, suggesting that the Ni NPs are coordinatively unsaturated.

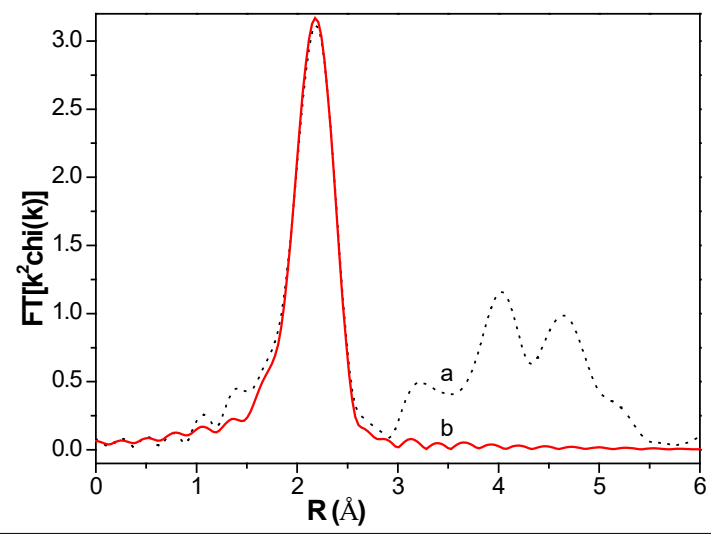

Figure S9. Curve fitting for Ni/MC-1/2-550 (red line).

\section{Catalytic properties}

We chose sorbitol hydrogenolysis as a probe reaction to investigate the catalytic performances of $\mathrm{Ni} / \mathrm{MC}-\mathrm{x}$-t series, as such reaction is a promising green process to produce important commodity chemicals from biomass instead of petroleum table 3, summarizes the catalytic results for the hydrogenolysis of sorbitol over various samples.

Table 3. Sorbitol conversion and product selectivity over various samples

\begin{tabular}{|c|c|c|c|c|c|c|c|c|c|}
\hline \multirow[b]{2}{*}{ Entry } & \multirow[b]{2}{*}{ Materials } & \multirow{2}{*}{$\begin{array}{c}\text { Metal } \\
\text { content } \\
\left(\text { mmolg }^{-1}\right)\end{array}$} & \multirow{2}{*}{$\begin{array}{c}\text { Sorbi- } \\
\text { tolcon- } \\
\text { version } \\
(\%) \\
(\%)\end{array}$} & \multicolumn{5}{|c|}{ Product selectivity $(\%)$} & \multirow[b]{2}{*}{ TON $^{d}$} \\
\hline & & & & 1,2-PG & EG & Sum & $\begin{array}{c}\mathrm{MeOH} \\
\text { and } \\
\mathrm{EtOH}\end{array}$ & $\begin{array}{l}\text { gaseous } \\
\text { products }^{c}\end{array}$ & \\
\hline 1 & $\mathrm{MC}$ & 0 & 3.0 & - & - & - & - & - & - \\
\hline 2 & Ni/MC-1/4-550 & 2.474 & 75.6 & 15.9 & 12.6 & 28.5 & 47.8 & 23.7 & 26.3 \\
\hline 3 & Ni/MC-1/2-550 & 3.940 & 86.0 & 12.7 & 12.4 & 25.1 & 46.9 & 28.0 & 18.8 \\
\hline 4 & Ni/MC-1/1-550 & 5.532 & 94.0 & 11.2 & 9.1 & 20.3 & 32.1 & 47.6 & 14.6 \\
\hline 5 & Ni/MC-1/4-750 & 2.215 & 37.3 & 14.5 & 11.0 & 25.5 & 39.5 & 35.0 & 14.5 \\
\hline 6 & Ni/MC-1/2-750 & 4.259 & 70.6 & 11.6 & 9.4 & 21.0 & 36.2 & 42.8 & 14.3 \\
\hline 7 & Ni/MC-1/1-750 & 4.400 & 54.4 & 9.0 & 6.4 & 15.4 & 30.8 & 53.8 & 10.6 \\
\hline 8 & Ni/MC-1/4-950 & 2.215 & 37.7 & 9.9 & 7.7 & 17.6 & 37.6 & 44.8 & 14.6 \\
\hline 9 & Ni/MC-1/2-950 & 3.578 & 41.6 & 9.5 & 7.5 & 17.0 & 35.0 & 48.0 & 10.0 \\
\hline 10 & Ni/MC-1/1-950 & 5.111 & 43.7 & 14.3 & 10.1 & 24.4 & 29.5 & 46.1 & 7.4 \\
\hline 11 & Ni/MC-1/2-550 (2nd) & - & 99.9 & 2.7 & 4.9 & 7.6 & 52.3 & 40.1 & - \\
\hline 12 & Ni/MC-1/2-550 (3rd) & - & 96.0 & 3.0 & 6.9 & 9.9 & 55.9 & 34.2 & - \\
\hline 13 & Ni/MC-1/2-550 (4th) & - & 98.5 & 1.0 & 1.6 & 2.6 & 48.8 & 48.6 & - \\
\hline 14 & Ni/MC-1/2-550 (5th) & - & 98.3 & 1.3 & 1.8 & 3.1 & 45.7 & 51.2 & - \\
\hline 15 & $\mathrm{Ni} / \mathrm{C}-1 / 2-550^{\mathrm{e}}$ & - & 9.6 & 3.7 & 7.5 & 11.2 & 36.9 & 51.9 & - \\
\hline
\end{tabular}

aReaction conditions: sorbitol $0.5 \mathrm{~g}$, catalyst $0.05 \mathrm{~g}, \mathrm{CaO} 0.5 \mathrm{~g}, \mathrm{H}_{2} \mathrm{O} 5.0$ $\mathrm{ml}, \mathrm{H}_{2}$ pressure $6 \mathrm{MPa}$, temperature $220^{\circ} \mathrm{C}$ and duration $4 \mathrm{~h}$.

b1,2-PG: 1,2-propylene glycol and EG: ethylene glycol.

cincluding $\mathrm{CH}_{4^{\prime}} \mathrm{H}_{2^{\prime}} \mathrm{C}_{2} \mathrm{H}_{6}$ and $\mathrm{C}_{3} \mathrm{H}_{8^{\prime}}$ etc.

'TON: (turnover number) moles of sorbitol converted per mole nickel.

ePrepared by pyrolysis of chitosan-nickel metal coordination polymer in the absence of P123.
It is clear that all Ni/MC-x-t catalysts show relatively higher sorbitol conversion (> 35.0\%) than MC (3.0\%), substantiating that the active sites are Ni NPs, not mesoporous support. However, Ni/C-1/2-550, comparatively prepared via pyrolysis of chitosan-nickel coordination polymer (Supporting Information), is lack of uniform mesopore distribution figure S10, and exhibits insignificant activity (9.6\%), suggesting the mesoporous arrays also play a role. In this study, the nanopores for $\mathrm{Ni} / \mathrm{MC}-\mathrm{x}$-t series are much larger (around 4.30 $\mathrm{nm})$ than the molecular dimensions of sorbitol $(0.67 \mathrm{~nm} \times$ $0.53 \mathrm{~nm} \times 0.29 \mathrm{~nm}$ ), facilitating mass transportation.

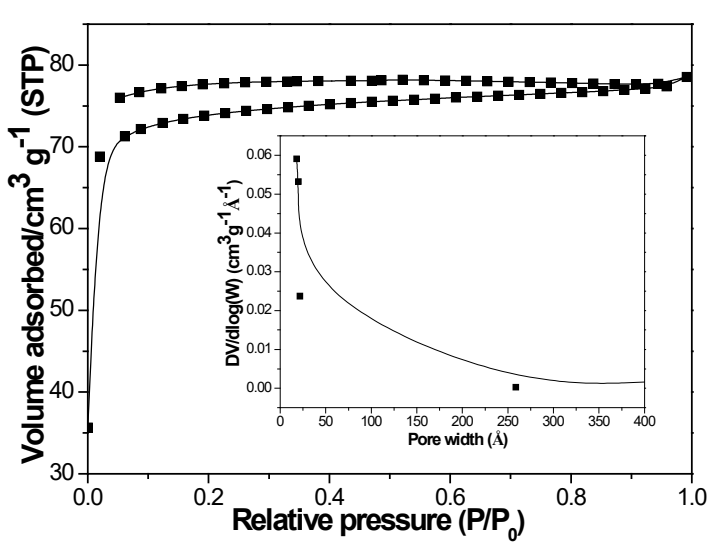

Figure $\mathrm{S} 10 . \mathrm{N}_{2}$ adsorption/desorption isotherm and $\mathrm{BJH}$ pore size distribution (inset) of $\mathrm{Ni} / \mathrm{C}-1 / 2-550$.

$\mathrm{Ni} / \mathrm{CTS}$ molar ratio and pyrolysis temperature affect the catalytic properties of $\mathrm{Ni} / \mathrm{MC}-\mathrm{x}-\mathrm{t}$ series significantly. As illustrated in table 3, except for Ni/MC-1/2-750, the sorbitol conversion improves with the increase of $\mathrm{Ni}$ content over different Ni/MC-x-550, Ni/MC-x-750 and Ni/MC-x-950 samples, respectively. For example, Ni/MC- $1 / 4-550$ shows $75.6 \%$ conversion of sorbitol, and Ni/MC-1/1-550 exhibits improved conversion of $94.0 \%$ (Table 3, entries 2-4), probably proportionate to the amount of available active Ni species in these catalysts. On the other hand, lower pyrolysis temperature is more beneficial to sorbitol conversion, since Ni/MC- $x-550$ series are more active than Ni/MC-x-750 and Ni/MC-x-950 series, verified by larger TON values. For nickel catalyzed sorbitol hydrogenolysis, the product distribution is complex because of various possible splitting styles of sorbitol under reaction conditions (Scheme S1). In this study, glycerol (GL), erythritol (C4-ol) and xylitol (C5-ol) are not detected. The selectivity to 1,2-PG is larger than to EG for all Ni/MC-x-t catalysts, though the total selectivity to $1,2-P G$ and $E G$ is no more than $30 \%$. These data demonstrate that glycol and glycerol are not the final products but the intermediate products which can undergo further hydrogenolysis to produce smaller species like EtOH, $\mathrm{MeOH}$ and gaseous products. The overall mass balances were always worse than $80 \%$, suggesting large conversion of sorbitol or intermediates into gaseous products [9]. From this point of view, the lower selectivity to 1,2-PG and EG can be understandable since the unsaturated intermediates produced via retro-aldol condensation cannot be hydrogenated over $\mathrm{Ni}$ catalysts, and thus they have to undergo some base-catalyzed by-reactions [20]. The $\mathrm{Ni}$ catalysts pyrolyzed at higher temperatures destroyed their selectivity to $1,2-P G$ and EG, maybe related to 
the large and irregular conglomeration of NPs. Among nickel based mesoporous carbons, Ni/MC-1/2-550 exhibits superior activity and total selectivity to $1,2-P G$ and $E G$, ascribed to the uniform spherical morphology and more coordinatively unsaturated nature.

The recoverability and stability of catalysts are further investigated. table 3 (entries 11-14) shows the recycling results of the representative Ni/MC-1/2-550. It is clear that $\mathrm{Ni} / \mathrm{MC}-1 / 2-550$ shows good recoverability without significant loss of activity even being recycled four times, though the total selectivity to 1,2-PG and EG decreases slightly. The Ni content in the filtrate was checked after the 1st use by ICPAES, showing insignificant loss of $0.08 \%$ of $\mathrm{Ni}$ species. It is acknowledged that sorbitol can form chelate complexes with nickel in aqueous solution, and thus most Ni-containing catalysts cannot be recycled [11]. Ce-promoted Ni catalyst shows enhanced stability [8], while the pure Ni nanocatalyst in this study can be recycled well, probably ascribed to the enhanced interaction between Ni NPs and support created simultaneously during pyrolysis.

\section{Conclusion}

A series of nickel based mesoporous carbons have been successfully fabricated via pyrolysis of chitosan-nickel superamolecular aggregates with different $\mathrm{Ni} / \mathrm{CTS}$ molar ratios at different temperatures. P123-directed self-assembly of CTS-HQ and nickel acetate guarantees the even dispersion of Ni species in the precursor composite Ni/CTS-P-x, rendering the homogeneously distributed Ni NPs inside the mesoporous carbonaceous framework after pyrolysis, and verified by various characterization techniques, such as high-energy $X$-ray diffraction, small-angle X-ray scattering, TEM, $\mathrm{N}_{2}$ adsorption/desorption and $\mathrm{X}$-ray absorption fine structure. Tuning of $\mathrm{Ni} / \mathrm{CTS}$ molar ratio and pyrolysis temperature results in $\mathrm{Ni} / \mathrm{MC}-1 / 2-550$ catalyst with superior activity, total selectivity to 1,2-PG and EG recycling stability for the hydrogenolysis of sorbitol. This is probably related to the uniform spherical Ni nanoparticles on mesoporous carbons, as well as its more coordinatively unsaturated nature.

\section{Acknowledgements}

We thank the proposals (GUP28010 and GUP31195) given by Advanced Photon Source of Office of Science, U.S. Department of Energy under Contract DE-AC02-06CH11357.

\section{References}

1. Chheda JN, Huber GW, Dumesic JA. Liquid-phase catalytic processing of biomass-derived oxygenated hydrocarbons to fuels and chemicals. Angew Chem Int Ed Engl. 2007; 46(38): 7164-7183. doi: 10.1002/ anie.200604274

2. Ruppert AM, Weinberg K, Palkovits R. Hydrogenolysis goes bio: from carbohydrates and sugar alcohols to platform chemicals. Angew Chem Int Ed Engl. 2012; 51(11): 2564-2601. doi: 10.1002/anie.201105125

3. Huber GW, Iborra S, Corma A. Synthesis of Transportation Fuels from Biomass: Chemistry, Catalysts, and Engineering. Chem. Rev. 2006; 106(9): 4044-4098. doi: 10.1021/cr068360d
4. Zhou CH, Xia X, Lin CX, Tong DX, Beltramini J. Catalytic conversion of lignocellulosic biomass to fine chemicals and fuels. Chem. Soc. Rev. 2011; 40(11): 5588-5617. doi: 10.1039/c1cs15124j

5. Yu WQ, Xu J, Ma H, et al. A remarkable enhancement of catalytic activity for $\mathrm{KBH}_{4}$ treating the carbothermal reduced Ni/AC catalyst in glycerol hydrogenolysis. Catal. Commun. 2010; 11(5): 493-497. doi : 10.1016/j. catcom.2009.12.009

6. Banu M, Venuvanalingam $P$, Shanmugam $R$, Viswanathan B, Sivasanker $S$. Sorbitol hydrogenolysis over $\mathrm{Ni}$, Pt and Ru supported on NaY. Top Catal. 2012; 55(11-13): 897-907. doi : 10.1007/s11244-012-9864-5

7. Hoffer BW, Prochazka R. US 2010/0019191 A1, 2010.

8. Ye LM, Duan XP, Lin HQ, Yuan YZ. Improved performance of magnetically recoverable Ce-promoted $\mathrm{Ni} / \mathrm{Al} 2 \mathrm{O} 3$ catalysts for aqueous-phase hydrogenolysis of sorbitol to glycols. Catal. Today. 2012; 183(1): 65-71. doi: 10.1016/j.cattod.2011.08.006

9. Banu $M$, Sivasanker $S$, Sankaranarayanan $T M$, Venuvanalingam $P$. Hydrogenolysis of sorbitol over $\mathrm{Ni}$ and Pt loaded on NaY. Catal. Commun. 2011; 12(7): 673-677. doi: 10.1016/j.catcom.2010.12.026

10. Wang XC, Meng LQ, Wu F, Jiang YJ, Wang L, Mu XD. Efficient conversion of microcrystalline cellulose to 1,2-alkanediols over supported $\mathrm{Ni}$ catalysts. Green Chem. 2012; 14(3): 758-765. doi: 10.1039/C2GC15946E

11. SchimpfS, Louis $\mathrm{C}, \mathrm{Claus} \mathrm{P} . \mathrm{Ni} / \mathrm{SiO}_{2}$ catalysts prepared with ethylenediamine nickel precursors: Influence of the pretreatment on the catalytic properties in glucose hydrogenation. Appl. Catal. A: Gen. 2007; 318: 45-53. doi: 10.1016/j.apcata.2006.10.034

12. van Ryneveld E, Mahomed AS, van Heerden PS, Green MJ, Friedrich HB. A catalytic route to lower alcohols from glycerolusing $\mathrm{Ni}$-supported catalysts. Green Chem. 2011; 13(7): 1819-1827. doi: 10.1039/C0GC00839G

13. Song $Q$, Wang $F, X u J$. Hydrogenolysis of lignosulfonate into phenols over heterogeneous nickel catalysts. Chem. Commun. 2012; 48(56): 7019-7021. doi: 10.1039/C2CC31414B

14. Lee J, Kim J, Hyeon T. Recent Progress in the Synthesis of Porous Carbon Materials. Adv. Mater. 2006; 18(16):2073-2094. doi: 10.1002/adma.200501576

15. Pang JF, Wang AQ, Zheng MY, et al. Catalytic conversion of cellulose to hexitols with mesoporous carbon supported $\mathrm{Ni}$-based bimetallic catalysts. Green Chem. 2012; 14(3): 614-617. doi: 10.1039/C2GC16364K

16. Li ZL, Liu JH, Huang ZW, Yang Y, Xia CG, Li FW. One-Pot Synthesis of Pd Nanoparticle Catalysts Supported on N-Doped Carbon and Application in the Domino Carbonylation. ACS Catal. 2013; 3(5): 839-845. doi: 10.1021/ cs400077r

17. Ma SQ, Goenaga GA, Call AV, Liu DJ. Cobalt Imidazolate Framework as Precursor for Oxygen Reduction Reaction Electrocatalysts. Chem. Eur. J. 2011; 17(7): 2063-2067. doi: 10.1002/chem.201003080

18. Kumar MNVR. A Review of Chitin and Chitosan Applications. React. Funct. Polym. 2000; 46(1): 1-27.

19. Guskos N, Typek J, Padlyak BV, et al. In situ synthesis, morphology and magnetic properties of poly(ether-ester) multiblock copolymer/carboncovered nickel nanosystems. J. Non-Cryst. Solids. 2010; 356(37-40): 18931901. doi: 10.1016/j.jnoncrysol.2010.07.014

20. Zhao L, Zhou JH, Chen H, Zhang MG, Sui ZJ, Zhou XG. Carbon nanofibers supported Ru catalyst for sorbitol hydrogenolysis to glycols: Effect of calcination. Korean J. Chem. Eng. 2010; 27(5): 1412-1418. doi: 10.1007/ s11814-010-0257-9

21. Corma A. From Microporous to Mesoporous Molecular Sieve Materials and Their Use in Catalysis. Chem. Rev. 1997; 97(6): 2373-2420. doi: $10.1021 / \mathrm{cr} 960406 \mathrm{n}$

22. Robles-Dutenhefner PA, Rocha KAD, Sousa EMD, Gusevskaya EV. Cobaltcatalyzed oxidation of terpenes: Co-MCM-41 as an efficient shape-selective heterogeneous catalyst for aerobic oxidation of isolongifolene under solventfree conditions. J. Catal. 2009; 265(1): 72-79. doi: 10.1016/j.jcat.2009.04.012

23. Gallo JMR, Pastore HO, Schuchardt U. Silylation of [Nb]-MCM-41 as an efficient tool to improve epoxidation activity and selectivity. J. Catal. 2006; 243(1): 57-63. doi: 10.1016/j.jcat.2006.07.002 
24. Maurya MR, Sikarwar S. Oxidation of phenol and hydroquinone catalysed by copper(II) and oxovanadium(IV) complexes of N,N'-bis(salicyledene) diethylenetriamine $\left(\mathrm{H}_{2}\right.$ saldien) covalently bonded to chloromethylated polystyrene. J. Mol. Catal. A: Chem. 2007; 263(1-2): 175-185. doi: 10.1016/j. molcata.2006.08.038

25. Sarma LS, Chen CH, Kumar SMS, et al. Formation of Pt-Ru Nanoparticles in Ethylene Glycol Solution: An in Situ X-ray Absorption Spectroscopy Study. Langmuir. 2007; 23(10): 5802-5809. doi: 10.1021/la0637418
26. Daniel OM, DeLaRiva A, Kunkes EL, Datye AK, Dumesic JA, Davis RJ. X-ray Absorption Spectroscopy of Bimetallic Pt-Re Catalysts for Hydrogenolysis of Glycerol to Propanediols. ChemCatChem. 2010; 2(9): 1107-1114. doi: $10.1002 /$ cctc.201000093

27. Qiao $B T$, Wang $A Q$, Yang $X F$, et al. Single-atom catalysis of $C O$ oxidation using Pt1/FeOx. Nat. Chem. 2011; 3(8): 634-641. doi: 10.1038/nchem.1095 